\title{
Visões da organização do trabalho: burocracia, taylorismo-fordismo, psicodinâmica do trabalho e a Proposta da Comissão de Procedimentos Operacionais da Empresa de Transportes e Trânsito de Belo Horizonte - BHTRANS $^{1}$
}

\author{
João Cesar Freitas Fonseca² e Ricardo Vinicius Cornélio de Carvalho ${ }^{3}$
}

RESUMO: O presente artigo discute, brevemente, alguns aspectos da organização do trabalho à luz do problema da prescrição e da realização do trabalho no serviço público, exemplificando-o através da experiência da Comissão de Procedimentos Operacionais da Empresa de Transportes e Trânsito de Belo Horizonte. Visa-se ressaltar os corolários da racionalização objetiva do trabalho que tem se fundamentado, exclusivamente, nos imperativos da eficiência gerencial, como uma oposição à "burocratização" do setor público. A discussão perpassa sucintamente as contribuições de Max Weber e de Frederick Winslow Taylor sobre o tema e apresenta a abordagem de Cristophe Dejours e da psicodinâmica do trabalho como uma explanação mais ampla acerca de como padrões rígidos e prescrições estáticas devem ser relaxados pela incorporação de uma perspectiva subjetiva da análise do trabalho.

PALAVRAS-CHAVE: Burocracia, taylorismo-fordismo, organização do trabalho, psicodinâmica do trabalho, procedimentos operacionais.

ABSTRACT: This paper briefly discusses some aspects of work organization considering mainly the prescribed work-real work problem at the public sector, herein exemplified by the Standard Operating Procedures Commission experience at the Transports and Transit Enterprise of the Belo Horizonte city. We intend to enhance the consequences of work rationalization founded exclusively on an efficiency management imperative, as an opposition to the traditional bureaucratic management at public sector. Our argument concisely deals with Max Weber and Frederick Winslow Taylor contributions to the theme, especially, related to work rationalization, and exposes Christophe Dejours and the psychodynamics of work approach as a broad explanation of how rigid patterns and steady prescriptions should be relaxed by the incorporation of a subjective perspective into work analysis.

KEYWORDS: Bureaucracy, taylorism-fordism, work organization, psychodynamics of work, operating procedures.

\footnotetext{
${ }^{1}$ Os autores agradecem às sugestões dos pareceristas anônimos que contribuíram para a melhoria deste artigo, ressaltando a isenção dos mesmos em qualquer erro e omissão nele ainda encontrados. Os autores agradecem ainda à BHTRANS e, em especial, à equipe da Gerência de Apoio Operacional (GEAOP).

${ }^{2}$ Doutor em Educação pela Universidade Federal de Minas Gerais. Professor Adjunto da Universidade Federal de São João Del Rei (UFSJ). E-mail: joaocesar.fonseca@yahoo.com.br.

${ }^{3}$ Pós-graduando em Gestão Pública pela Fundação João Pinheiro. Analista de Administração e Finanças da BHTRANS. E-mail: ricardo.cornelio@pbh.gov.br.
} 


\section{Introdução}

O desenvolvimento do setor público brasileiro operou-se conjuntamente à formação histórica e socioeconômica de industrialização tardia do país, portanto, sua organização não se furta às tensões contraditórias do mundo do trabalho delineadas pela paleta desse tipo de sociedade capitalista, de textura dependente e contraditória. Nesse sentido, a gestão pública em geral, e a organização do trabalho, em específico no setor público, têm acompanhado tais vicissitudes histórico-econômicas, tendo sido operadas de forma errática, instável, variando ao longo da mudança de paradigmas de administração pública (KEINERT, 1994) e ao sabor de modelos de gestão patrimonialistas (FAORO, 2001), burocráticos ou tecnoburocráticos, ou gerencialistas (BRESSER-PEREIRA, 1996; 1998).

Tal contexto aduz à compreensão de que, no Brasil, a "trajetória da administração pública representa uma construção histórica de reveses, mudanças de rota, [e] períodos de completa inércia” (TORRES, 2008, p. 140), o que leva à constatação de que “não há homogeneidade no modelo brasileiro de administração pública” (OLIVEIRA, 2007, p. 272). Isso não impede a ocorrência, ainda que pontual ou episódica, de processos semelhantes ao que poderia se chamar de isomorfismo ${ }^{4}$ entre o setor público e o privado, ou dentro das várias instâncias do setor público (DIMAGIO e POWELL, 2007). Recentemente, isto tem se evidenciado pela adoção de práticas gerenciais privadas no setor público, como suposta forma de imbuir racionalidade e eficiência a esse segmento, o que poderia estar aproximando o discurso e a prática de gestão nos dois âmbitos.

Essa incorporação de práticas de gestão privada no setor público não tem isentado a gestão de pessoas. Na esfera pública, isso tem sido apresentado como uma mudança organizacional que promoverá a evolução natural da gestão pública rumo à eficiência, fundada na simples adoção unidimensional de modelos gerenciais pretensamente universais e inovadores, como o gerencialismo. Acreditamos, entretanto, que o momento atual estaria

\footnotetext{
${ }^{4}$ Este processo denominado de Isomorfismo se "constitui [de] um processo restritivo que força uma unidade de uma população a se assemelhar às outras unidades que enfrentam o mesmo conjunto de condições ambientais”. Duas formas mais comuns seriam identificáveis: o isomorfismo competitivo e o institucional. O isomorfismo institucional seria mais adequado à compreensão da vida organizacional moderna, cujas mudanças decorreriam das suas versões coercitiva ou coerciva, mimética, ou normativa. O isomorfismo mimético "resulta de respostas padrão à incerteza"; o coercitivo, "resulta das pressões ao mesmo tempo formais e informais exercidas sobre as organizações por outras organizações das quais dependem e por expectativas culturais da sociedade em que as organizações atuam” (DIMAGGIO e POWELL, 2007, p. 121-122). O Isomorfismo competitivo resulta das pressões de concorrência no mercado.
} 
mais próximo de um conceito de crise de matiz gramsciano que propriamente de evolução gerencial. No caso da gestão de pessoas na esfera pública, por exemplo, coexistiriam um velho modelo tradicional com ênfase na organização formal do trabalho, herdeiro da Administração Burocrático-Patrimonialista, e um novo, ou pretensamente novo, com ênfase nos resultados do trabalho, defendido pela Nova Administração Pública (NAP) ${ }^{5}$. Entretanto, argumentamos que a inovação gerencialista não teria superado a tradição burocrática definitivamente. ${ }^{6}$ Embora tenham discursos distintos, ela continuaria negligenciando as contradições existentes nas relações de trabalho e as implicações destas na subjetividade dos trabalhadores, promovendo ao final apenas um retorno às práticas de padronização do processo de trabalho originárias do taylorismo-fordismo, que também são típicas na burocracia. Estaria configurado assim, o ambiente de crise em que o velho é tido como morto e o novo não consegue nascer, pois não promove a ruptura necessária à mudança (GRAMSCI, 1978).

De qualquer maneira, ao tangenciarem o público e o privado, acostam-se também as problematizações de ambos. Nesse sentido, certas dificuldades referentes à organização do trabalho no setor público e no setor privado aproximar-se-iam não só pelo fato de ambos comungarem do mesmo pano de fundo histórico-social, o da sociedade capitalista que os ampara, i.e., o de uma sociedade que segue reproduzindo os antagonismos comuns à lógica do capital, referenciados em oposições como: capital e trabalho; execução e planejamento; liberdade e necessidade; autorrealização e alienação; exploração e emancipação; prescrição e realização; aspectos esses responsáveis por uma vasta gama de injunções e sofrimentos de ordem física e psíquica nos trabalhadores (DEJOURS, 1994; MERLO e LAPIS, 2007; FARIA e MENEGHETTI, 2007a; 2007b; FERREIRA e MENDES, 2001).

Entretanto, para além da problematização exposta, o atual cenário da gestão pública brasileira que propugna pela emulação direta de discursos e práticas do setor privado

\footnotetext{
${ }^{5}$ Ana Paula Paes de Paula (2005, p. 27) sintetiza bem a origem e o significado da Nova Administração Pública. Segundo a autora, "os movimentos neoconservadores buscaram aumentar a eficiência do Estado se baseando nas propostas neoliberais e nas recomendações da teoria da escolha pública. No contexto da crise do Estado, essas visões se somaram ao movimento gerencialista, resultando em uma abordagem de reforma e gestão do Estado que ficou conhecida como nova administração pública e que se caracteriza por ter transformado as ideias, os valores e as práticas cultivados no domínio da administração de empresas em um referencial para o setor público".

${ }^{6}$ A indispensável reflexão critica sobre os discursos inovadores adotados de forma recorrente pelos gestores tem sido objeto da atenção de autores importantes, sendo possível remeter o leitor aos textos de Grey (2004) e Aktouf (1996) e Gaulejac (2007).
} 
preconizados pelo gerencialismo e pela NAP (PAULA, 2005a; 2005b) estaria reforçando ainda mais as possibilidades de sofrimento, adoecimento e antissublimação dos trabalhadores desse segmento. Na medida em que aumentam as indefinições quanto ao modo de gerir as relações de trabalho no setor público, i.e., em que se propaga a crise da gestão de pessoas na esfera pública, fecunda-se o campo para a angústia.

Com efeito, é razoável supor que, ao interpolar concepções organizacionais distintas (gestão pública e gestão privada), obrigando o servidor público a submeter-se às práticas gerenciais do setor privado, com as quais ele não familiariza o seu processo identitário com o serviço público, seria deturpado por uma lógica privatista que ele não reconhece. Ademais, o modus operandi proposto pela NAP deveria requerer certo acautelamento ao lidar com a prescrição e realidade do trabalho no serviço público, visto se tratar de uma organização que já tradicionalmente caminharia para exorbitar o nível de regramentos, haja vista a tradicional crítica ao rigorismo, ao formalismo e à burocratização do setor público. Desse modo, emergiria desse quadro - emoldurado em permanentes contradições - uma grande possibilidade de conflitos entre a objetivação e a subjetivação no processo de trabalho no âmbito público, situações estas que, irresolutas, causariam ainda mais focos de sofrimento ao reforçar cargas psíquicas negativas nas relações de trabalho (BOUYER, SZNELWAR e COSTA, 2006; PAIVA e COUTO, 2008; LANCMAN e UCHIDA, 2003).

Existem diversas formas de se aproximar da realidade organizacional para se tentar compreender as possibilidades, as restrições e as consequências que o cenário descrito acima traz para as relações de trabalho no setor público. Uma delas é a que este artigo se propõe, a de uma percepção crítica que busca enxergar essas “instâncias obscuras” da subjetividade no processo de trabalho (FARIA, 2007, p. 3). Obscuras para a burocracia desumanizada que Weber observou e para a organização racional ou científica do trabalho que Taylor defendeu, uma vez que ambas enxergavam o método e a forma, mas não viam o sujeito; eram visões sobre a organização do trabalho que não enxergavam o trabalhador.

Dessa forma, parte-se de uma análise sucinta da organização do trabalho sob a ótica da burocracia weberiana, para relacioná-la com o mesmo objeto visto pelos pressupostos tayloristas-fordistas. O objetivo é suscitar um questionamento à naturalização da ideia de que a resposta à ineficiência do setor público (ou à burocratização do setor público) deve vir unicamente pela idealização da prescrição, representada aqui por propostas de 
padronização do trabalho para gerar eficiência. Esse entendimento, na concepção dos autores, apenas propaga as reificações dos processos sociais por meio da racionalidade instrumental, conforme a análise crítica indica (ALVESSON e DEETZ, 2007; FARIA, 2007; VIEIRA e CALDAS, 2007). E, além disso, acaba por provocar um distanciamento cada vez maior entre o trabalho prescrito e o efetivamente realizado pelo servidor.

Para nos auxiliar nessa abordagem, trazemos a contribuição da Psicodinâmica do Trabalho, principalmente com Dejours (1994) e Dejours e Abdouchelli (1994a; 1994b). Aqui, se buscará expandir a concepção de organização do trabalho com a inclusão de uma perspectiva que considera além das tarefas prescritas, as atividades, o sujeito, o seu contexto e a sua história, propondo um cruzamento da objetividade com a subjetividade no modo de realização do trabalho. A ideia central é que o taylorismo-fordismo somente reforça a impessoalidade que a burocracia, formalista por excelência, já prevê e, com isso, aumenta a potencialidade de sofrimento no trabalho, adicionando um problema à gestão de pessoas quando acredita estar resolvendo um problema de ineficiência.

Por fim, uma pequena exemplificação é apresentada através da experiência da Comissão de Procedimentos Operacionais da Empresa de Transportes e Trânsito de Belo Horizonte (BHTRANS), com vistas a ilustrar, principalmente, dois aspectos: (1) uma maneira alternativa de aproximação à prescrição da realização do trabalho no setor público; (2) as consequências que a supervalorização da norma de conduta padronizada pode trazer para as relações de trabalho, quando se desconsidera a interssubjetividade que as compõem. Acredita-se que, se é possível supor que no setor privado o trabalho com sentido é o trabalho feito de maneira eficiente e o trabalho eficiente é aquele que tem sentido (MORIN, 2007), e que pode ocorrer um equilíbrio entre competitividade e humanização através de um compromisso ético com foco nas pessoas (VERGARA e BRANCO, 2007), então, o setor público também pode (e deve) ser pensado como um espaço em que deve prevalecer a visão da organização do trabalho que vê o próprio trabalho como resultado de uma tarefa, mas sobretudo como resultado do esforço e do empenho de uma pluralidade de sujeitos. 
O sacerdócio da razão instrumental: as organizações burocráticas weberianas e a organização racional do trabalho sob a égide do taylorismo-fordismo

Ao analisar as características da organização burocrática, Motta e Bresser-Pereira (2004, p. 44), em determinado momento, destacam a sacralização da adesão à regra e à forma, como ápice da impessoalidade racional desse tipo de organização. Dizem os autores que, nesse caso “o formalismo se transforma em ritualismo”, e assim, “o funcionário [passa a ser] o sacerdote que aplica a norma ritual sem discutir. Não importa que as condições circundantes tenham mudado”. De fato, o próprio Max Weber identificara que em organizações burocráticas “o cumprimento 'objetivo’ das tarefas significa, primordialmente, um cumprimento de tarefas segundo regras calculáveis e 'sem relação com pessoas’” (WEBER, 1946/1982, p. 250, grifos no original), portanto, um cumprimento racional, mas desumanizado. A vantagem desse tipo de organização seria que o comportamento humano minuciosamente exaurido pela norma asseguraria uma previsibilidade capaz de garantir sempre que as mesmas ações, racionalmente premeditadas, sejam estreitamente executadas de modo a gerar os melhores resultados possíveis de eficiência.

Para auferir tal resultado, a organização deveria conseguintemente combinar alguns pressupostos indeclináveis à burocratização e que são também os principais aspectos de uma burocracia no sentido weberiano, quais sejam: (1) garantia de que a autoridade derive “de normas racional-legais, em vez de tradicionais”, i.e., que sejam legitimadas pelo seu caráter racional e não pelo costume; (2) assegurar que “as normas [sejam] escritas e exaustivas”, i.e., que prescrevam a totalidade do mundo que regem, sem margens para dubiedades; (3) promover o "seu caráter hierárquico”, i.e., apresentar uma estrutura escalonada rígida e bem determinada; e (4) possuir "uma divisão horizontal do trabalho, em que as diferentes atividades são distribuídas de acordo com os objetivos a serem atingidos”, i.e., estabelecer metas para cada conjunto de tarefas (MOTTA e BRESSER-PEREIRA, 2004, p. 15-17).

É importante salientar, no entanto, que o conceito de racionalidade considerado pela burocracia é um conceito instrumental, que reduz a racionalidade a um cálculo de meios e fins que gerará um dado nível de eficiência. Trata-se de uma racionalidade de um sujeito incompleto, em cuja formação não se encontram caracteres psíquicos de quaisquer 
natureza. Assim, nesse caso, a “eficiência é uma forma específica de racionalidade, na qual a coerência dos meios em relação com os fins visados se traduz no emprego de um mínimo de esforços (meios) para a obtenção de um máximo de resultados (fins)” (MOTTA e BRESSER-PEREIRA, 2004, p. 32). Tal argumento, bastante utilitarista, coaduna-se à concepção da burocracia também como forma de dominação, posto que "a razão conveniente, formal, instrumental, não consegue mais guiar os homens na direção da emancipação” (FARIA, 2007, p. 9), mas à sujeição irrestrita à regra. O raciocínio utilitarista, porém, serve apenas para legitimar a dominação hierárquica representada na estrutura burocrática, jamais para libertar, não sendo por acaso que Weber valer-se-ia da metáfora da "jaula ou gaiola de ferro" que a racionalidade burocrática representaria para a humanidade. Nessa burocracia, observa-se, então, a redução do todo abstrato da razão à eficiência concreta de razões práticas, meramente focadas "numa determinada situação”, em que "tais razões valem para determinado ator, que tem determinadas preferências e quer atingir determinadas metas” (HABERMAS, 2002, p. 24).

Os aspectos relacionados a recursos humanos nesse tipo de organização seriam voltados, portanto, apenas à prescrição do agir e ao treinamento impessoal da técnica fria, visando expurgar a sensibilidade das relações de trabalho e impedir algum tipo de subjetivação do trabalhador. Desse modo, diz-nos Weber (1982, p. 230-231): “a administração burocrática [...] pressupõe treinamento especializado e completo", uma vez que "o desempenho do cargo segue regras gerais, mais ou menos estáveis, mais ou menos exaustivas, e que podem ser aprendidas”; logo, a única preocupação seria treinar profissionais para que aprendessem exatamente quais ações executar conforme as descrições precisas dos procedimentos formalmente determinados pela autoridade hierarquicamente competente. Dessa forma, chega-se à conclusão de que “a administração de um cargo [...] se baseia em documentos escritos (os arquivos), preservados em sua forma original ou em esboço” (WEBER, 1982, p. 230), tal como se vê nos manuais de procedimentos operacionais difundidos nas organizações contemporâneas; bastaria, portanto, escrevê-los, divulgá-los e controlá-los, para se ter devidamente organizadas as relações de trabalho da organização.

Com efeito, esse aspecto do rigor burocrático-formal repercute ainda hoje nas organizações como legado ainda não superado da visão mecânica das relações de trabalho. A esse respeito, Hall (2004, p. 66) afirma que “a formalização, por sua própria natureza, ocupa um 
papel central na vida das organizações”, na medida em que “a especificação de regras, procedimentos, penalidades e demais aspectos predeterminam muito do que ocorre em uma organização”. Diante disso, uma das formas de se compreender o sistema social de uma organização perpassa, inexoravelmente, o conhecimento de suas regras e prescrições formais. Evidentemente, algum grau de formalização é inerente às organizações como estruturas sociais institucionalizadas, mas o que se ressalva aqui é a alienação que a exacerbação da regra desumanizada pode acarretar ao indivíduo. Temos, assim, a evidência de que os limites da absolutização da prescrição, como única e inescapável alternativa para a garantia e consolidação das próprias organizações, parecem se fazer notar com cada vez maior clareza.

Similarmente, em alguns aspectos, a análise de Frederick Taylor (1856-1915) acerca da organização do trabalho em muito se assemelha a esse universo burocrático descrito por Weber. Taylor ocupou-se, principalmente, do método prático de operacionalizar os ganhos de eficiência decorrentes da especialização e da decomposição do trabalho. Para tanto, conforme relembra Morgan (2009), ele defendeu uma série de princípios, dentre os quais se destacam: (1) transferir a responsabilidade da organização do trabalho do empregado para o gerente; (2) usar métodos científicos para determinar a forma mais eficiente de executar as tarefas; (3) selecionar a melhor pessoa para desempenhar as atividades; (4) treiná-la para executar as tarefas conforme os métodos prescritos; e (5) fiscalizar o seu desempenho. A esse conjunto de princípios e análises de processos de trabalho desenvolvidos a priori, por Taylor, denominou-se Organização Racional ou Científica do Trabalho (ORCT).

A abordagem taylorista cuidou, então, de demonstrar “a potencialidade da administração (management) para produzir ganhos econômicos através do estabelecimento de práticas e padrões de trabalho baseados em métodos científicos” (SILVA, 1987, p. 15). Nesse sentido, racionalizar o trabalho, para Taylor, significava parametrizar práticas e tarefas segundo uma análise sistemática dos tempos e movimentos inculcados no processo de trabalho, de modo a promover a máxima produtividade advinda da especialização, tendo como substrato a promoção de uma dicotomia básica (que seria extremamente questionada pelos críticos ${ }^{7}$

\footnotetext{
${ }^{7}$ As Escolas das Relações Humanas e Behaviorista ou Comportamental fundamentam grande parte da crítica, em Administração, à Escola da Administração Científica. Para uma crítica mais radical, ver Braverman (1987).
} 
da Administração Científica ${ }^{8}$ ), e a oposição planejamento versus execução. Nas palavras do próprio Taylor (1995, p. 26): “O objetivo mais importante de ambos, trabalhador e administração, deve ser a formação e o aperfeiçoamento do pessoal da empresa, de modo que os homens possam executar em ritmo mais rápido e com maior eficiência os tipos mais elevados de trabalho, de acordo com suas aptidões naturais” (grifos nossos).

Com Henry Ford, a principiologia taylorista experimentou uma difusão extraordinária, sobretudo no pós-guerra. Ford aplicou à produção o rigor metodológico procurado por Taylor, e, com sua linha de produção, alcançou níveis de produtividade de grande notoriedade, acompanhados de maior controle e intensificação do trabalho, e acirramento da relação capital/trabalho. ${ }^{9}$ Com o fenômeno fordista em ação, a literatura se ocupou por traçar a linha Taylor-Ford, que demarcaria não só uma forma de se pensar as relações de trabalho nas organizações capitalistas, mas, também, como uma cosmovisão da sociedade capitalista de meados do século XX. Inauguram-se, simultaneamente, a universalização tanto da produção de massa quanto do consumo de massa. Assim, os propósitos generalistas de Taylor, que via em suas ideias o verdadeiro motor da prosperidade, ${ }^{10}$ se espraiam pelas organizações do mundo todo, legando-nos ainda hoje grande influência no mundo organizacional. ${ }^{11}$

Tanto a burocratização quanto a organização racional ou científica do trabalho ganharam força e dinâmica na sociedade capitalista. Isto ocorreu de tal forma que muitos autores identificam o modo de produção fordista, suas repercussões sociais na sociedade de consumo e a coexistência de um Estado de Bem-Estar Social, como um período específico

\footnotetext{
${ }^{8}$ Costuma-se tomar a Escola da Administração Científica tendo Frederick Winslow Taylor (1856-1915) como precursor. Segundo Chiavenato (2003, p. 48), essa "escola era formada principalmente por engenheiros", como o próprio Taylor, que "galgou sucessivamente os postos de apontador, chefe de turma, assistente de contramestre, mecânico-chefe, desenhista-chefe, engenheiro-chefe" (SILVA, 1987, p. 58). Além dele, outros nomes mormente vinculados à Escola são os de Henry Lawrence Gantt (1861-1919), Frank Bunker Gilbreth (1868-1924), Lilian Gilbreth (1878-1961), Harrington Emerson (1853-1931), Carl Barth (1860-1939) e Henry Ford (1863-1947).

${ }_{9}$ De acordo com Cipolla (2003, p. 84), Ford mecanizou a exploração Taylorista que antes dependia da supervisão direta do administrador. Assim, "a transformação da manufatura em esteira transforma o taylorismo numa imposição da própria tecnologia. Tempos e movimentos adequados não são mais uma determinação externa ao trabalhador e, portanto, passível de oposição, mas uma necessidade de adaptação do próprio trabalhador ao ritmo do trabalho coletivo agora ditado não pelo próprio trabalho coletivo, mas pela velocidade do transporte do produto em processo através dos trabalhadores da fábrica. Assim, quando o taylorismo advém de um sistema mecânico temos o que se chama de fordismo" (grifos no original).

${ }^{10}$ Conforma ressalta Benedicto Silva (1987, p. 18), "Taylor via em seu sistema a chave de algo muito mais importante do que o bom funcionamento das empresas industriais. Para ele, a administração científica poderia conduzir a humanidade a dias muito melhores, talvez a um estágio de abundância, talvez à solução de todos os conflitos entre o capital e o trabalho”.

${ }^{11}$ A este respeito, diz Morgan (2007, p.35) que "enquanto Taylor é frequentemente visto como um vilão que criou a administração científica, é importante ter em mente que ele foi realmente parte de uma tendência social mais ampla que envolve a mecanização da vida de uma forma geral”.
} 
do capitalismo que combinava o modelo taylorista-fordista de organização das relações sociais de trabalho sob a lógica do capital e aparato burocrático do Estado Keynesiano (HARVEY, 1993; BOYER, 1990; LIPIETZ, 1988). Nesse sentido, Gramsci (1978b) já apontava uma estreita relação do fordismo a um novo tipo de sociedade, consumista e reprodutora da exploração do homem pelo capital. É preciso compreender, no entanto, que não foi tão-somente o mundo capitalista que experimentou a epopéia da organização racional do trabalho e do culto à burocracia; o exemplo socialista da URSS é comumente citado como sendo, também, um expoente desta natureza.

\section{Críticas à visão taylorista-fordista do trabalho e à racionalidade instrumental burocrática: a organização do trabalho para além do previsível e do padronizado}

A racionalidade burocrática se espraiou pelo mundo, mais como máxima da eficiência que como efetividade. Afinal, a racionalização prevista no modelo burocrático weberiano era um tipo ideal concebido pelo sociólogo alemão e não subsistia tal como descrito. Tal como afirmam Motta e Bresser-Pereira (2004, p. 43), se “o segredo da maior eficiência das burocracias está na possibilidade de previsão efetiva do comportamento dos membros das organizações. Na prática, entretanto, isso jamais se verifica inteiramente”, posto que a pluralidade de comportamentos segue à pluralidade de sujeitos e leva à multiplicação da imprevisibilidade.

Não haveria, pois, como se evocar tal previsibilidade contra a multidimensionalidade dos indivíduos que cada organização incorpora, e cujos comportamentos se inter-relacionam sinergicamente, amoldando-se, transformando-se; tensionando-se e distendendo; conformando uma imensa variedade de ações racionais e afetivas, imersas em realidades particulares e coletivas distintas. Movediços, tais comportamentos se consubstanciam em um amálgama de subjetividade inatingível à simplicidade estática da conduta prescrita. Talvez, por isso mesmo o tipo ideal weberiano surge mais como alerta que como meta. Giddens (1991, p. 17) reconhecera isto ao qualificar Weber como “o mais pessimista entre os três patriarcas fundadores” da sociologia, vez que o sociólogo alemão estava "vendo o mundo moderno como um mundo paradoxal onde o progresso material era obtido apenas à custa de uma expansão da burocracia que esmagava a criatividade e a autonomia individuais”. 
O taylorismo-fordismo também não destoa muito desta visão lúgubre. Por mais que se insuflassem os ganhos de produtividade e eficiência, suas práticas extremadas também findaram por gerar problemas físicos e psíquicos nos trabalhadores, uma vez que lhes implicava um sacrifício demasiadamente pesado, tanto objetiva quanto subjetivamente, ao esvaziar-lhes o conteúdo do trabalho ao mesmo tempo em que o intensificavam em termos de carga necessária à sua execução. Ao fazê-lo, cerceavam e desumanizavam-lhes o agir, de tal modo que ao cabo predestinavam aos trabalhadores o fardo daqueles "que não podem mais ser sujeitos de seu comportamento”, mas apenas reificação do desejo do empregador (DEJOURS e ABDOUCHELI, 1994, p. 42).

A esse respeito, Lancman e Uchida (2003, p. 79) afirmaram que "Taylor (1995), quando propôs a Organização Científica do Trabalho (OCT) [...], aparentemente buscou eliminar a subjetividade do trabalho por meio do controle dos corpos dos trabalhadores cindidos de suas mentes". Por isso mesmo que Merlo e Lapis (2007, p. 63) argumentaram que "no modelo taylorista, a principal fonte de agressão à saúde do trabalhador é a própria organização do trabalho" (MERLO e LAPIS, 2007, p. 63), haja vista que muito além de ser apenas uma decomposição de tarefas é, também, um mecanismo de dominação e violência. Nas palavras de Faria (2007a, p.209) "tal sistema permite [...] não apenas definir a 'melhor maneira de produzir', mas subsidiar as gerências com um padrão de avaliação e controle do trabalho e dos trabalhadores” que lhes promoverá uma agressão psíquica em razão de incorrer em "exploração dos aspectos psicológicos do sujeito trabalhador em favor da organização"; por meio, dentre outros fatores, de angústias como as "do sofrimento em realizar bem as tarefas, da ansiedade de ver o seu trabalho ser reconhecido ou pelo menos não questionado, da frustração de não ser valorizado pelo trabalho desenvolvido" (FARIA e MENEGHETTI, 2007a, p. 287).

Além disto, depõe contra a racionalização burocrática e taylorista-fordista a incansável busca de previsibilidade e padronização. Ora, a realidade organizacional é permeada de imprevisibilidade, tanto do sujeito trabalhador quanto da própria situação de trabalho, que nunca se repete. Como o segundo mergulho no rio, a que fazia menção Heráclito de Éfeso, posto que a cada instante, tanto o mergulhador quanto o rio são distintos do momento anterior. A exigência feita ao trabalhador de agir sobre o imprevisto, o inesperado, principalmente se consideradas as condições burocráticas, tayloristas e fordistas de 
organização, produz inevitavelmente empecilhos à gestão de pessoas, visto que "nesta condição, o trabalho constitui a gestão de imprevistos, que provavelmente, configurar-se-ão como problemas a serem resolvidos” e não como características do sujeito, racional e emocionalmente engajado no trabalho (ABRAHÃO e TORRES, 2004, p. 70).

A padronização, quando exorbitada, também seria uma incongruência, pois, conforme Dejours e Abdoucheli (1994, p. 41): “e se a multiplicidade dos modos operatórios escondesse precisamente a multiplicidade dos Sujeitos?” Seria possível que todos agissem da mesma forma? É concebível sempre haver o mesmo procedimento, e para todos? O trabalho efetivamente realizado tem como ser idêntico ao prescrito? Mas, ao mesmo tempo, seria possível imaginar uma organização sem um mínimo de prescrição, padronização e burocratização? Estas são algumas das perguntas a que o arcabouço teórico da Psicodinâmica do Trabalho nos auxilia a responder.

\section{A racionalização ampliada: a organização do trabalho segundo a psicodinâmica do trabalho e a experiência da comissão de procedimentos operacionais da empresa de transportes e trânsito de Belo Horizonte}

Apesar das críticas apresentadas, as reformas propostas ao setor público brasileiro têm se assentado na tentativa de desfazer a "burocracia” do setor público importando práticas do setor privado. Assim, tomando como exemplo o caso específico do Estado de Minas Gerais, ${ }^{12}$ uma parte do arcabouço teórico que fundamenta o “choque de gestão” propugna pela ideia de que "as funções operacionais ocupam muito tempo das pessoas de uma empresa e são centradas na padronização. Não pode haver nada mais importante! [...], portanto, gerenciar é estabelecer novos padrões, modificar os padrões existentes ou cumprilos. A padronização é o cerne do gerenciamento” (FALCONI, 2004, p. 26). Dessa forma, “os gerentes de empresas públicas, de acordo com essa tendência, devem procurar a máxima eficiência na administração do 'negócio’, conforme os moldes da gestão de

\footnotetext{
${ }^{12}$ É importante observar que apesar de optarmos neste texto por analisar uma empresa do âmbito da Administração Pública Municipal, o Choque de Gestão adotado pelo Governo do Estado de Minas Gerais parece exercer significativa influência nos discursos, ações e representações dos diferentes atores sociais implicados na gestão de serviços públicos no estado mineiro, em geral, e na sua capital, em particular. São exemplos destas similitudes o próprio modelo de gestão atualmente em desenvolvimento na capital mineira onde figurarão "Projetos Sustentadores", tais como existem os "Projetos Estruturadores” no Estado, a definição de "Áreas de Resultado", também nos moldes do modelo estatal, e, o uso de consultorias privadas para modernizar a gestão.
} 
empresas privadas, nas quais o resultado é um dos principais indicadores de sucesso" (PAIVA e COUTO, 2008, p. 1.195). Mas que resultado? E obtido a qual nível de sacrifício do trabalhador? A simples padronização do processo de trabalho não seria suficiente para assegurar esta almejada eficiência, pois, para tanto, é necessário que a realidade ocorra exatamente como o que fora prescrito, o que costuma não ocorrer.

Ao gestor público não restaria alternativa, senão, seguir a orientação: "assegure-se de que todos os Operadores, em todas as turmas, que executem a mesma tarefa, estejam conduzindo o seu trabalho da mesma maneira” (FALCONI, 2004, p. 56). Porém, conforme discute Dejours e Abdoucheli (1994, p. 41), "e se cada modo operatório não fosse um comportamento mudo, mas o compromisso entre Desejo e Realidade, elaborado individualmente por cada trabalhador?”. Nesse sentido, a eficiência almejada poderia desencadear um processo de esgotamento, fadiga, sofrimento e adoecimento do trabalhador que não só deterioram a fundamentação fria da padronização, mas também a questionam do ponto de vista ético, sobre o valor moral da organização do trabalho que ignora a formação psíquica do sujeito. Nesse caso, essa racionalização taylorista-fordista e a burocratização traduzir-se-iam em aflição e angústia, o que redundou, nos estudos de Dejours e Abdoucheli, na constatação de que "a organização do trabalho aparece na clínica psicopatológica como a expressão da violência que pode implicar uma generalização na ordem da técnica”.

Porém, como a pergunta que encerra a seção anterior sugere, não seria possível que uma instituição sem um mínimo de organização do trabalho, e pensar um mundo em que todo trabalho seja necessariamente sofrimento é imaginar o mundo da existência impossível, da felicidade ausente. Daí o salto epistemológico da psicopatologia do trabalho para a psicodinâmica do trabalho. ${ }^{13}$ A organização do trabalho não seria mediadora apenas da dor, mas também do prazer no ato de trabalhar e nas relações de trabalho, i.e., consoante a maneira como o sujeito trabalhador e as condições de trabalho forem consideradas pelos

\footnotetext{
${ }^{13}$ Segundo Heloani e Lancman, (2004, p. 82), “a Psicodinâmica do Trabalho busca compreender os aspectos psíquicos e subjetivos que são mobilizados a partir das relações e da organização do trabalho. Busca estudar os aspectos menos visíveis que são vivenciados pelos trabalhadores ao longo do processo produtivo, tais como: mecanismos de cooperação, reconhecimento, sofrimento, mobilização da inteligência, vontade e motivação e estratégias defensivas que se desenvolvem e se estabelecem a partir das situações de trabalho”. Dessa forma, “a organização do trabalho [é] a responsável pelas consequências penosas ou favoráveis para o funcionamento psíquico do trabalhador” (MENDES, 1995, p. 34). Ao passo que “a organização do trabalho aparece na clínica psicopatológica como a expressão da violência que pode implicar uma generalização na ordem da técnica”.
} 
gestores, a psicodinâmica do trabalho sugere que "é a organização do trabalho a responsável pelas consequências penosas ou favoráveis para o funcionamento psíquico do trabalhador” (MENDES, 1995, p. 34, grifos nossos).

Conforme salientam Abrahão e Pinho (2002, p. 47), “nessa abordagem, o trabalhador é o sujeito ativo do processo, pois a depender da situação com a qual é confrontado, ele transforma permanentemente a sua atividade, como forma de responder às demandas que se apresentam”. Com isso, a padronização e a regra podem ser ferramentas úteis tanto para a melhoria quanto para a precarização do trabalho, pois o sujeito trabalhador é um sujeito responsivo, que erige estratégias de defesas conscientes e inconscientes, que racionaliza o trabalho não do ponto de vista utilitarista, mas do ponto de vista da complexidade e da perplexidade. Por conseguinte, "se o trabalhador é capaz de pensar o trabalho, de elaborar essa experiência ao falar, de simbolizar o pensamento e chegar a uma interpretação, ele tem a possibilidade de negociar, de buscar um novo sentido partilhado, de transformar e fazer a organização do trabalho evoluir” (LANCMAN e UCHIDA, 2003, p. 86). Dessa forma, cada sujeito ao trabalhar modificará, com suas peculiaridades e história, a forma de se trabalhar, impedindo que haja apenas um modo agir, tal como apenas um modo de ser.

Uma das formas de avaliar essas relações se dá através da perquirição da dualidade, prescrição e realidade. Pelo exposto anteriormente, tem-se que a padronização determinada pela ORCT mediante um procedimento operacional padrão (POP) elaborado, como usualmente acontece, por um gestor especialista em um cargo superior, de forma escrita, formalizada, é uma norma burocrática, visto ser uma regra racional, legal, impessoal e hierarquicamente legitimada. E, sendo assim, seria pretensamente uma prescrição de um modo de agir. Uma determinação exaustiva de conduta. ${ }^{14}$ Segundo Falconi (1990; 2004), o procedimento operacional padrão (POP) ou standard operation procedure (SOP) é um instrumento da qualidade total essencial para o gerenciamento da rotina de trabalho. Tratase de um documento formal, escrito (por vezes, pictórico), que descreve uma única sequência correta de tarefas prioritárias a serem realizadas em um processo de trabalho.

\footnotetext{
${ }^{14}$ Ironicamente, a incorporação de procedimentos operacionais padronizados nos moldes do setor privado, dadas as características desse tipo de procedimento (racionalidade instrumental, utilitarista, desumanizada), finda por acarretar justamente uma neo-burocratização no setor público, apesar de ser comumente apresentada como forma de combater a "burocracia”, tomada aqui como “excesso de entraves formais”. Ou seja, tenta-se racionalizar uma organização por ser formal em demasia, através da formalização de novos processos.
} 
Segundo esse autor, qualquer desvio do POP durante a realização daquela atividade representa uma "anomalia” e exige uma ação corretiva. Portanto, o POP representa a decomposição de uma atividade em tarefas que deverão sempre ser feitas de uma mesma maneira, na mesma ordem, por qualquer indivíduo que seja responsável por aquela atividade.

Ora, sob os auspícios da psicodinâmica do trabalho, Borges (2004, p. 47) assevera que: “o trabalho, definitivamente, não pode mais ser visto como uma sequência de operações repetidas, programadas, padronizadas, mas torna-se uma sequência de eventos que se cruzam, modificam-se e ultrapassam o saber e a ação de um único indivíduo”. Dessa forma, lança-se suspeição sobre a generalização e a universalização das tarefas propostas nas prescrições padronizadas.

É baseado nisto que se pode compreender que o trabalho é mais do que uma mera dimensão técnica, restrita e atomizada. Não existe só a tarefa, em si; coexistem tarefas e sujeitos, equipes e processos, internalizações e externalizações; importa determinar o que se faz, mas também importa compreender quem faz, e como este sujeito lida com as dimensões das tarefas que executa. Ora, nesse sentido, a psicodinâmica do trabalho se aproxima da ergonomia, onde, também, os “estudos demonstram uma diferença entre o que é previsto e o que é realizado, entre o desejável e o real, pois nas situações de trabalho ocorrem variações frequentes, em decorrência de vários fatores. Dentre eles, vale ressaltar a organização do trabalho bem como aqueles relacionados às características do trabalhador” (ABRAHÃO, 2000, p. 51). Assim:

Se, em estruturas organizacionais tayloristas, acreditava-se que apenas seguir as normas, os procedimentos escritos e as prescrições, era suficiente para se realizar o trabalho, os estudos ergológicos sustentam o que o movimento dos trabalhadores já afirmava: a prescrição nunca é suficiente para dar conta da produção exigida. $\mathrm{O}$ trabalho real (efetivamente realizado) exige sempre uma mobilização cognitiva e afetiva do trabalhador. O trabalho, na realidade, nunca é só mera execução (BORGES, 2004, p. 43). 
Vejamos, então, a experiência da Comissão de POP da BHTRANS. A BHTRANS é uma empresa pública do município de Belo Horizonte cuja finalidade precípua, definida no decreto que a instituiu, ${ }^{15}$ é de planejar as atividades de transporte e trânsito da capital de Minas Gerais. Na letra da lei, em seu art. $4^{\circ}$, tem-se que a BHTRANS: "tem por objeto todo o planejamento, a organização, a direção, a coordenação, a execução, a delegação e o controle da prestação dos serviços públicos relativos ao transporte coletivo e individual de passageiros, tráfego, trânsito e sistema viário do Município de Belo Horizonte”.

Boa parte dessas atividades, tidas como mais ostensivas, são realizadas pelos seus agentes de trânsito. De acordo com o Anexo I, do Código de Trânsito Brasileiro (doravante, CTB), o agente da autoridade de trânsito é a "pessoa, civil ou policial militar, credenciada pela autoridade de trânsito para o exercício das atividades de fiscalização, operação, policiamento ostensivo de trânsito ou patrulhamento", e fiscalização é o “ato de controlar o cumprimento das normas estabelecidas na legislação de trânsito, por meio do poder de polícia administrativa de trânsito, no âmbito de circunscrição dos órgãos e entidades executivos de trânsito e de acordo com as competências definidas neste Código”.

Tais agentes, comumente denominados de fiscais, estabelecem, entre outros aspectos, o contato direto com o cidadão ao se substabelecerem nas vias e logradouros públicos de Belo Horizonte em atividades de rotina operacional que em sua maioria visam à aplicação das normas do código de trânsito brasileiro. Decorre desse fato a descrição recorrente na empresa de que eles são “a BHTRANS na rua”, como forma de simbolizar a responsabilidade que carregam ao atuar autonomamente, mas devidamente coordenados, fora do ambiente interno da organização, agindo diretamente nas várias regiões da cidade quando são identificados metonimicamente pelos cidadãos como sendo a BHTRANS em sua integralidade.

Com efeito, em sua situação laboral, os agentes de trânsito se encontram demasiadamente expostos, posto que suas atividades, por mais que sejam programadas, lidam flagrantemente com o imprevisto (dos acidentes de trânsito à conduta dos concidadãos inconformados), e

\footnotetext{
${ }^{15}$ Trata-se do Decreto Municipal N. ${ }^{\circ}$ 7.298, de 5 de agosto de 1992, que regulamento a Lei Municipal n 5.953, de 31 de julho de 1991, que autorizou o executivo da capital mineira a constituir a BHTRANS. Houve demais alterações decorrentes de outros decretos, mas que escapam ao interesse deste trabalho.
} 
ainda carregam o peso da imagem, pois como corporificação da empresa que representam, encampam-lhes todas as críticas como se a eles fossem designadas. Convivem cotidianamente com a oscilação do emocional oriunda da organização do trabalho, que vem tanto da tensão e pressão devidos ao conflito direto com cidadãos quanto da própria mutabilidade do real frente à exiguidade da prescrição operacional programada. Conforme apontam Lancman et al. (2007, p. 81), "a natureza do serviço prestado nem sempre agrada aos munícipes (fiscalização, cobrança e restrição do uso do espaço público, emissão de multas etc.)”. O poder de polícia exercido pelos mesmos, ao restringir diretamente direitos e ao aplicar penalidades administrativas, expõe-nos ao risco e à reação adversa. Destarte, “o contato direto com os usuários, por vezes torna esses trabalhadores [...] alvos e anteparo de irritação, insatisfação, revolta e agressões, que estariam, na maior parte das vezes, destinadas às instituições que eles representam”.

Diante disso, os agentes têm tido sua imagem demasiadamente questionada pela sociedade, ao mesmo tempo em que têm sua importância relevada pelos órgãos públicos; uma medida simbólica de tentativa de reconhecimento é a institucionalização de sua relevância. ${ }^{16}$ Isto, porém, findaria por promover "um conflito identitário entre a importância, legitimidade e credibilidade que atribuem àquilo que fazem, ao esforço despendido para o trabalho, e a falta de reconhecimento social” (LANCMAN et al, 2007, p. 81). E, em meio a esse amálgama de condições propícias ao sofrimento e ao conflito, insurge a necessidade da regra como forma de permitir, tal como se entende na BHTRANS, a definição de procedimentos operacionais para "evitar o desgaste do agente e do cidadão", preservando ambas as partes sem prejudicar a aplicabilidade do CTB.

Nesse sentido, haveria uma crença no procedimento operacional padronizado como mecanismo de defesa dos agentes em face dos infortúnios a que se expõem, mas, também, como instrumento de organização do trabalho. Como definem Dejours e Abdoucheli (1994b, p. 125), a organização do trabalho possui, "por um lado, a divisão do trabalho: divisão de tarefas entre operadores, repartição, cadência e, enfim, o modo operatório prescrito", que seria o documento escrito definindo exaustivamente as formas de agir do

\footnotetext{
${ }^{16}$ Nesse sentido, a Lei Municipal n. ${ }^{\circ}$ 8.925/04, e sua alteração pela Lei Municipal n. ${ }^{\circ}$ 9.369/07, que instituiu o Dia Municipal do Agente de Trânsito, antes em 21 de maio e atualmente em 18 de setembro.
}

CADERNOS GESTÃO PÚBLICA E CIDADANIA, V. 14, N. 54 - JAN./JUNHO DE 2009 
trabalhador; e "por outro lado a divisão de homens: repartição de responsabilidades, hierarquia, comando, controle etc.”, i.e., quem faz o quê. Porém, seria possível tal documento abarcar toda a variabilidade de situações de trabalho que os agentes deparam?

Conforme visto, um dos problemas da visão burocrática é o excessivo apego às regras. De certa forma, a padronização proposta pela Comissão de POP BHTRANS caminha para a burocratização, no sentido que busca imbuir uma racionalidade impessoal na conduta dos agentes. Se entendermos que o CTB, com seus 341 artigos, define uma série de regras a serem observadas pelos agentes em sua rotina de trabalho, que consistem, em essência, em sua aplicação, um POP nada mais seria que prescrever ainda mais uma ação já demasiadamente prescrita. Assim, sabendo que existem hoje, na BHTRANS - entre vigentes e em discussão -, 29 procedimentos referentes ao trânsito, 7 administrativos, 7 emergenciais e 7 sobre atividades em estações de ônibus, somando-se todo o regramento da legislação de trânsito em vigor, o resultado inevitável seria o completo distanciamento do prescrito do POP da realidade dos agentes, a começar pela impossibilidade de conhecer o seu vasto conteúdo.

De fato, é pela grande recorrência à gerência responsável pela coordenação das atividades da Comissão de POP para sanar dúvidas que se percebe que os POPs não são muito bem conhecidos por boa parte dos agentes. Assim, ao invés de provocar eficiência, a existência de tantos POPs nada mais seria que "burocratização”, em sentido pejorativo, como “papelada”, inerte, e longe de conseguir amparar a conduta do agente na rua, que é fluida, cercada de imprevisibilidade. Porém, a Comissão de POP acredita estar certa ao emular a proposta defendida pelo setor privado de padronização, tentando esgotar as possibilidades de conduta dos envolvidos, pois, como discutido, esta seria a única possibilidade de se auferir eficiência no setor público, garantindo que "todos atuem da mesma maneira”, inexoravelmente.

Entretanto, o acompanhamento das atividades operacionais dos agentes nos permite ver que é impossível que todos se comportem da mesma maneira, pois a forma de lidar com o cidadão muda de acordo com o perfil e a personalidade do agente, bem como o modo com que cada agente segue as orientações de seus coordenadores ou com os demais colegas de trabalho. Da mesma forma, mesmo em atividades mais simples, como equipar a viatura com a sinalização necessária (cones, balizadores, barreiras plásticas etc.), por mais que haja 
um POP de seis páginas prescrevendo o modo como o fazer, detalhando quem o faz e como o fazer, cada agente realiza tal atividade de forma distinta; inclusive, relacionam-se de modos diferentes com os ajudantes que os auxiliam nessa tarefa. Por mais que o POP tente, não conseguirá prescrever qual deverá ser a reação desse auxiliar diante do pedido de assistência do agente para carregar a viatura com os equipamentos de sinalização viária, ou diante da orientação (como prediz o referido documento) de que "realize tal atividade sozinho”.

Um exemplo recente sobre como o excesso de prescrições pode provocar a carga psíquica negativa sobre os agentes refere-se às atividades de remoções de veículos, que atualmente ficam a cargo de uma subconcessionária. Essa subconcessionária disponibiliza os reboques para a remoção de veículos em situação de infração, mas cuja operacionalização há de ser amparada e fiscalizada pelo agente a bordo. Existem procedimentos operacionais na BHTRANS que determinam a maneira como se deve executar tal atividade: prescrevendo o exato papel do reboquista e dos agentes; a forma de proceder; o tipo de veículo; os documentos a serem lavrados; e as orientações a serem informadas aos cidadãos. Porém, tais documentos não impediram que se colidissem os interesses e se gerasse um conflito.

Do ponto de vista taylorista-fordista, o esforço de racionalidade utilitarista teria sido satisfeito e o trabalho estaria acabado; bastaria cobrar-se do agente a conduta prescrita para obter-se o resultado eficiente. Porém, como o trabalho envolve mais que a mera razão instrumental, não estavam previstos os problemas que decorreriam do julgamento subjetivo do agente, que insatisfeito com a natureza da prestação do serviço, a cargo de uma empresa subcontratada, se recusa a realizar remoções que considera incoerentes com o interesse coletivo e amparadas por uma lógica privada de lucratividade não coincidente com a lógica pública de preservação “do melhor para a cidade”.

Dessa forma, em depoimentos apresentados em reuniões gerenciais, surgiram testemunhos de insatisfação, frustração e tristeza que impediram a execução do serviço e que "fizeram parar pra pensar sobre o meu trabalho", tornando "sem sentido" realizá-lo de um modo que se julgava moralmente equivocado, como foi dito por um dos agentes. A forma de execução, o reboque, a situação de infração eram similares, mas alguns agentes, devido às suas formações psicossociais específicas, sentiram "um grande mal-estar" em agir da mesma forma em qualquer dos casos. Note-se que aqui eles questionam não apenas o modo 
operatório, mas também o sentido da prescrição de agir sob a lógica do capital que seria diferente do agir sob a lógica do interesse público; por mais que o conteúdo da tarefa fosse o mesmo, os sujeitos trabalhadores não o são.

O desgaste psíquico se intensificou de modo que ocorressem reclamações da contratada de que suas atividades estavam sendo prejudicadas, o que gerou insatisfação por parte dos agentess que passaram a ter dificuldades de lidar com os condutores dos reboques (reboquistas), alegando pressões para agir em desconformidade com o que acreditavam ser a finalidade operacional. Após o relato do fato em reunião na gerência responsável pelo acompanhamento desse contrato, a quantidade de ausências justificadas ao trabalho da equipe de agentes envolvida com as atividades de remoção aumentou, de janeiro a junho de 2009, 97\%. O aumento mais relevante foi no mês seguinte ao que se apresentou a reclamação, em que as ausências justificadas aumentaram cerca de 200\%, tendo reduzido após posicionamento formal da empresa para resolver a situação. Cumpre destacar que, durante as discussões, levantou-se a hipótese de o problema decorrer do procedimento estabelecido, que seria "inadequado" para o bom funcionamento do trabalho em equipe de agentes e dos funcionários terceirizados, embora fosse “adequado” do ponto de vista da forma de proceder às remoções. Ou seja, o procedimento não esgotava a complexidade subjetiva que o trabalho realmente exigia. Cabe destacar ainda que, em média, no período após os relatos, $80 \%$ das ausências justificadas decorreram de atestados e licenças médicas. O índice de absenteísmo que vinha diminuindo no início do ano de 2009 sofreu uma forte inflexão em meados do ano.

Da mesma forma, se apenas a regra fosse suficiente, pela letra fria do código bastaria aplicar a multa para que muitas das atividades dos agentes se realizassem proficientemente. Mas a conduta do agente permite ver que a orientação, a cortesia e o juízo de ponderação da regra fazem com que se proceda de modo alternativo ao prescrito, de modo a ser "mais justo com o cidadão”, o que por vezes é mais bem visto e valorizado pelo próprio cidadão que a estrita aplicação da lei. As ações de orientação são usualmente mais bem compreendidas como educativas; o que, pela definição da regra, extrapola a atividade do agente de apenas aplicar o código.

Igualmente, há o risco de que a prescrição venha a tornar-se um fim em si e que atravanque o procedimento ao invés de racionalizá-lo, tal como ocorrera com o mesmo procedimento 
de carregamento da viatura com sinalização em que houve grande discussão sobre quem deveria fazê-lo. Não havendo consenso sobre o assunto nas reuniões da Comissão de POP, dispensaram-se modos operatórios distintos que foram questionados e acabaram por se ameaçar a não sair para as atividades de rotina enquanto não houvesse um POP descrevendo literalmente como proceder, exemplificando-se com "todas as palavras possíveis”, todas as ações necessárias.

Por isso, frisa-se que também a ausência de procedimentos pode agravar e prejudicar as situações de trabalho, posto que o conflito e a angústia quanto à situação descrita anteriormente geraram desgaste emocional nos membros da comissão e entre algumas equipes de trabalho quanto à forma correta de se proceder. Por isso que a Comissão de POP possui um interesse a mais. Trata-se de um espaço de deliberação coletivo, não de uma regra imposta, mas avençada entre pares, pois os próprios agentes são indicados pelas respectivas gerências para participar da reunião que ocorre semanalmente e visam deliberar sobre questões envolvendo os diversos modos operatórios existentes, apontando soluções para os problemas emergentes. É uma forma de democratizar em algum grau a organização do trabalho e de aproximá-la da realidade, posto que exemplos como os citados neste trabalho foram apresentados pelos próprios participantes que sobre eles debatem de modo a identificar os desvios que a regra provoca e os limites de sua aplicação.

O espaço público criado pela Comissão de POP enquadra-se como sendo um espaço político; em que as relações de poder tentam ser suavizadas de modo a evitar que prescrições natimortas sejam elaboradas e, ao mesmo tempo, ensejar o redesenho de processos que dêem oportunidade não só à otimização procedimental do modo operatório, mas que avaliem as condições de trabalho dos sujeitos envolvidos, suas experiências e suas necessidades. Tal ato tem contado com o respaldo da diretoria, que valoriza a iniciativa em situações mais agudas - como o ocorrido em relação ao problema das remoções -, onde a discussão em pauta na Comissão foi peremptoriamente recomendada.

Contudo, por vezes, persiste o vício de que a letra corrigirá a conduta e a padronização solucionará toda a insatisfação no trabalho, o que é falho. É preciso procurar mais do que a mera definição de modos operatórios para se obter satisfação no trabalho, mas, de qualquer forma, a existência desse espaço é uma boa ideia para a organização do trabalho no setor 
público, que merece ser desenvolvida, e não a mera imitação do setor privado na adoção de métodos que este considera universalmente adequados.

\section{Considerações finais}

Buscando manter coerência com a proposição de um ensaio crítico, buscou-se, nesse texto, fazer avançar a discussão em torno do sentido e do significado da busca - aparentemente irrefreável - adotada por segmentos da sociedade em torno da prescrição absoluta dos procedimentos a serem adotados pelos agentes públicos nas organizações de prestação de serviços, como paradigma absoluto e idealizado; isentos de falhas na medida em que plenamente reproduzidos pelos sujeitos que os executam.

Não é esta a realidade que tem sido possível observar. O aumento crescente dos afastamentos e licenças de servidores públicos, das diferentes esferas de governo, tem sido objeto da denúncia de entidades sindicais e análises epidemiológicas, com clara tendência de deslocamento dos chamados distúrbios osteomusculares para os transtornos mentais, em suas diferentes manifestações.

Torna-se imprescindível assumir a pertinência do debate multidisciplinar, não ignorando as complexidades em torno da gestão de áreas de interesse central das sociedades, como a saúde, a educação, a segurança pública, a mobilidade e a moradia, para mencionar apenas aquelas que parecem encontrar eco mais profundo nos programas eleitorais, mas sempre esquecidas enquanto dimensão cotidiana do trabalho concreto realizado pelos servidores públicos.

Os exemplos citados, em relação às atividades dos agentes de trânsito da BHTRANS, trazem à tona a questão de que também o setor público comunga das dificuldades de organização do trabalho; concomitantemente, a experiência da Comissão de POP da referida empresa surge como um espaço de deliberação interessante para o tratamento dessas questões, de forma talvez mais inovadora do que o mero processo mimético de incorporação de soluções do setor privado. Trabalhos futuros poderão ser desenvolvidos, aprofundando os temas esboçados nesse documento. 


\section{Referências}

ABRAHÃO, J. I. Reestruturação produtiva e variabilidade do trabalho: uma abordagem da ergonomia. Psicologia: Teoria e Pesquisa, v. 16, n. 1, p. 49-54, 2000.

ABRAHÃO, J. I.; PINHO, D. L. M. As transformações do trabalho e desafios teóricometodológicos da ergonomia. Estudos de Psicologia, n. 7, p. 45-52, 2002.

ABRAHÃO, J. I.; TORRES, C. C. Entre a organização do trabalho e o sofrimento o papel de mediação da atividade. Revista Produção, v. 14, n. 3, p. 67-76, 2004.

AKTOUF, O. Traditional management and beyond: a matter of renewal. Quebec: Gaetan Morin, 1996.

ALVESSON, M.; DEETZ, S. Teoria crítica e abordagens pós-modernas para estudos organizacionais. In: CLEGG, S.; HARDY, C.; NORD, W. R. (Orgs.) Handbook de estudos organizacionais: modelos de análise e novas questões em estudos organizacionais. São Paulo: Atlas, 2007.

BORGES, M. E. S. Trabalho e gestão de si: para além dos “recursos humanos”. Cadernos de Psicologia Social do Trabalho, v. 7, p. 41-49, 2004.

BOUYER, G. C.; SZNELWAR, L. I.; COSTA, M. J. B. Subjetivação e sofrimento no trabalho: o "si” que “se” produz na atividade. Memorandum, v. 11, p. 43-58, 2006.

BOYER, R. A teoria da regulação: uma análise crítica. São Paulo: Nobel, 1990.

BRAVERMAN, H. Trabalho e capital monopolista: a degradação do trabalho no século XX. Rio de Janeiro: LTC, 1987.

BRESSER-PEREIRA, L. C. Da administração pública burocrática à gerencial. Revista do Serviço Público, v. 47, n. 1, 1996.

BRESSER-PEREIRA, L. C. Uma reforma gerencial da administração pública no Brasil. Revista do Serviço Público, v. 49, n. 1, 1998.

CHIAVENATO, I. Introdução à teoria geral da administração: uma visão abrangente da moderna administração das organizações. $7^{a}$ ed. Revisada e atualizada. Rio de Janeiro: Elsevier, 2003 
CIPOLLA, F. P. Economia política do taylorismo, fordismo e teamwork. Revista de Economia Política, v. 23, n. 3, p. 78-93, 2003.

DEJOURS, C. A carga psíquica do trabalho. In: DEJOURS, C.; ABDOUCHELI, E.; JAYET, C. Psicodinâmica do trabalho: contribuições da escola dejouriana à análise da relação prazer, sofrimento e trabalho. São Paulo: Atlas, 1994.

DEJOURS, C.; ABDOUCHELI, E. Desejo ou motivação? A interrogação psicanalítica sobre o trabalho. In: DEJOURS, C.; ABDOUCHELI, E.; JAYET, C. Psicodinâmica do trabalho: contribuições da escola dejouriana à análise da relação prazer, sofrimento e trabalho. São Paulo: Atlas, 1994.

DEJOURS, C.; ABDOUCHELI, E. Itinerário teórico em psicopatologia do trabalho. In: DEJOURS, C.; ABDOUCHELI, E.; JAYET, C. Psicodinâmica do trabalho: contribuições da escola Dejouriana à análise da relação prazer, sofrimento e trabalho. São Paulo: Atlas, 1994b.

DIMAGGIO, P. J.; POWELL, W. W. Jaula de ferro revisitada: isomorfismo institucional e racionalidade coletiva nos campos organizacionais. In: CALDAS, M. P.; BERTERO, C. O. (Coord.) Teoria das organizações. São Paulo: Atlas, 2007.

FALCONI, V. Gerenciamento da rotina do trabalho do dia-a-dia. Nova Lima: INDG Tecnologia e Serviços, 2004.

FALCONI, V. Qualidade total: padronização de empresas. Belo Horizonte: Fundação Cristiano Ottoni, 1990.

FAORO, R. Os donos do poder: formação do patronato político brasileiro. São Paulo: Globo, 2001.

FARIA, J. H. A fase do colaboracionismo: a nova prática sindical. In: FARIA, J. H. (Org.) Análise crítica das teorias e práticas organizacionais. São Paulo: Atlas, 2007a.

FARIA, J. H. Os fundamentos da teoria crítica: uma introdução. In: FARIA, J. H. (Org.) Análise crítica das teorias e práticas organizacionais. São Paulo: Atlas, 2007.

FARIA, J. H.; MENEGHETTI, F. K. A instituição da violência nas relações de trabalho. In: FARIA, J. H. (Org.) Análise crítica das teorias e práticas organizacionais. São Paulo: Atlas, 2007a. 
FARIA, J. H.; MENEGHETTI, F. K. O sequestro da subjetividade. In: FARIA, J. H. (Org.) Análise crítica das teorias e práticas organizacionais. São Paulo: Atlas, 2007b.

FERREIRA, M. C.; MENDES, A. M. Só de pensar em vir trabalhar, já fico de mau humor: atividade de atendimento ao público e prazer-sofrimento no trabalho. Estudos de Psicologia, v. 6, n. 1, p. 93-104, 2001.

GAULEJAC, V. Gestão como doença social: ideologia, poder gerencialista e fragmentação social. Aparecida: Idéias \& Letras, 2007

GIDDENS, A. As consequências da modernidade. São Paulo: UNESP, 1991.

GRAMSCI, A. Obras escolhidas. São Paulo: Martins Fontes, 1978.

GRAMSCI, A. Americanismo e fordismo. In: GRAMSCI, A. Obras escolhidas. São Paulo: Martins Fontes, 1978b.

GREY, C. O fetiche da mudança. RAE-revista de administração de empresas, v. 44, n. 1, p. 10-25, 2004.

HABERMAS, J. Uma visão genealógica do teor cognitivo da moral. In: HABERMAS, J. Inclusão do outro: estudos de teoria política. São Paulo: Loyola, 2002. p. 13-62.

HALL, R. H. Organizações: estruturas, processos e resultados. São Paulo: Pearson Prentice Hall, 2004.

HARVEY, D. Condição pós-moderna: uma pesquisa sobre as origens da mudança cultural. São Paulo: Loyola, 1993.

HELOANI, R.; LANCMAN, S. Psicodinâmica do trabalho: o método clínico de intervenção e investigação. Revista Produção, v. 14, n. 3, p. 77-86, 2004.

KEINERT, T. M. M. Os paradigmas da administração pública no Brasil (1900-92). RAErevista de administração de empresas, v. 43, n. 3, p. 41-48, 1994.

LANCMAN, S.; UCHIDA, S. Trabalho e subjetividade: o olhar da psicodinâmica do trabalho. Cadernos de Psicologia Social do Trabalho, v. 6, p. 79-90, 2003.

LANCMAN, S.; SZNELWAR, L. I.; UCHIDA, S.; TUACEK, T. A. O trabalho na rua e a exposição à violência no trabalho: um estudo com agentes de trânsito. Interface Comunicação, Saúde, Educação, v. 11, n. 21, p. 79-92, 2007. 
LIPIETZ, A. Miragens e milagres: problemas da industrialização no terceiro mundo. Tradução de Marie Mathieu. São Paulo: Nobel, 1988.

MENDES, A. M. B. Aspectos psicodinâmicos da relação homem-trabalho: as contribuições de C. Dejours. Psicologia, Ciência e Profissão, v. 15, n. 1-3, p. 34-38, 1995.

MERLO, A. R. C.; LAPIS, N. L. A saúde e os processos de trabalho no capitalismo: reflexões na interface da psicodinâmica do trabalho e da sociologia do trabalho. Psicologia e Sociedade, v. 19, n. 1, p. 61-68, 2007.

MORIN, E. M. Sentidos do trabalho. In: WOOD JR., T. (Coord.) Gestão empresarial: o fator humano. São Paulo: Atlas, 2007.

MORGAN, G. Imagens da organização. São Paulo: Atlas, 2009.

MOTTA, F. C. P.; BRESSER-PEREIRA, L. C. Introdução à organização burocrática. São Paulo: Pioneira Thomson Learning, 2004.

OLIVEIRA, C. G. O servidor público brasileiro: uma tipologia da burocracia. Revista do Serviço Público, v. 58, n. 3, p. 269-302, 2007.

PAIVA, K. C. M.; COUTO, J. H. Qualidade de vida e estresse gerencial "pós-choque de gestão”: o caso da Copasa-MG. Revista de Administração Pública, v. 42, n. 6, p. 1.1891.211, 2008.

PAULA, A. P. P. Por uma nova gestão pública: limites e potencialidades da experiência contemporânea. Rio de Janeiro: FGV, 2005a.

PAULA, A. P. P. Administração pública brasileira entre o gerencialismo e a gestão social. RAE-revista de administração de empresas, v. 45, n. 1, p. 37-49, 2005.

SILVA, B. Taylor e Fayol. Rio de Janeiro: FGV, 1987.

TAYLOR, F. W. Princípios de administração científica. São Paulo: Atlas, 1995.

TORRES, M. D. F. Estado, democracia e administração pública no Brasil. Rio de Janeiro: FGV, 2008.

VERGARA, S. C.; BRANCO, P. D. Empresa humanizada: a organização necessária e possível. In: WOOD JR., T. (Coord.) Gestão empresarial: o fator humano. São Paulo: Atlas, 2007. 
VIEIRA, M. M. F.; CALDAS, M. P. Teoria crítica e pós-modernismo: principais alternativas à hegemonia funcionalista. In: CALDAS, M. P.; BERTERO, C. O. (Coord.) Teoria das organizações. São Paulo: Atlas, 2007.

WEBER, M. Ensaios de sociologia. Rio de Janeiro: LTC, 1982.

Artigo recebido em 15/09/2009. Aprovado em 14/11/2009. 